University for Business and Technology in Kosovo

UBT Knowledge Center

Nov 2nd, 9:00 AM - Nov 3rd, 5:00 PM

\title{
Quality Development and Organizational Renovation at Construction Companies
}

\author{
Esat Gashi \\ University for Business and Technology
}

Follow this and additional works at: https://knowledgecenter.ubt-uni.net/conference

Part of the Architecture Commons

\section{Recommended Citation}

Gashi, Esat, "Quality Development and Organizational Renovation at Construction Companies" (2012). UBT International Conference. 8.

https://knowledgecenter.ubt-uni.net/conference/2012/all-events/8

This Event is brought to you for free and open access by the Publication and Journals at UBT Knowledge Center. It has been accepted for inclusion in UBT International Conference by an authorized administrator of UBT Knowledge Center. For more information, please contact knowledge.center@ubt-uni.net. 


\title{
Quality Development and Organizational Renovation at Construction Companies
}

\author{
Cand PhD . Es at Gashi MSc. Grad. Civ. Eng, ${ }^{1}$ \\ ${ }^{1}$ University for Business and Technology \& University of Prishtina, Kosovo
}

Abstract: Today, companies working in construction engineering field are facing with the process of quality development. We believe that only the companies which will implement interchanges of organisational renovation or reengineering from the quality viewpoint will be able to offer holistic quality answers to the customer's needs and their preferences. For that reason it is important that company retains its ability of ongoing monitoring of organizational model of viewpoints of quality management in order to:

- Realize, how responsible the company controls and operates its relations with quality according to its competitors,

- Identify, which components of organisational model of quality management are more important than others are,

- Analyse the level of organisational efficiency of quality management from the viewpoints of business and quality criteria of funning business.

All mentioned present the basic orientation of the organization in order that quality expectations will be effectively fulfilled according to the goals of our business partners and other stakeholders.

Key words: change of organization, organization, quality development, quality management

\section{Introduction}

Renovation Process or lately so called re-engineering process is currently one of the most popular catchwords. Construction Companies as other Companies in Industry hope to break the "magic triangle" of costs, time and quality by streamlining their business processes. So far, most re-engineering process projects have concentrated on stationary industries, mainly manufacturing. Others, such as the construction industry, have not gained as much attention yet, even though there is a high need for reducing costs and improving the effectiveness in this industry. Increasing customer demands towards quality, speed and flexibility, tough competition from international companies, and reduced public spending have created a difficult situation for many companies.

The principles of re-engineering process, i.e. the fundamental rethinking of the way things are done by a company, can be applied to the construction industry, as well. However, it is not possible to use the experiences from the stationary industry without any changes, but it is necessary to take the industry -specific requirements into account and to develop new solutions for construction companies. Companies working in Civil Engineering industry face a high complexity which makes it difficult to re-design and manage the business processes. On the other hand, this complexity increases the need to improve the business processes and to develop integrated solutions for supporting these processes with information technology.

Re-engineering process is concerned with whether assured production-driven tasks and functions are necessary in a customer-driven process. It involves major (radical) changes to the existing processes and inflicts change in the teams' thought processes, as they have to rethink the way a job is currently done. This is the distinguishing factor between process re-engineering and automation of tasks and functions, although both see technology and in particular, Information Technology (IT) as principal drivers. Company reengineering is a top-down approach, led by top management, and aimed at rapid and dramatic performance improvement (Ardhaldjian \& Fahner 1994). Its primary purpose is to increase the effectiveness of a company's management, administrative and operational tasks (Scott 1995). It views the business from the process perspective rather than the functional or organisational (Klein 1994), and is intended to align the business processes with the strategic objectives and customers' needs.

We believe that only the companies which will implement interchanges of organisational renovation or reengineering from the quality viewpoint will be able to offer holistic quality answers to the customer's needs and 
their preferences. For that reason it is important that company retains its ability of on-going monitoring of organizational model of viewpoints of quality management in order to:

- Realize, how responsible the company controls and operates its relations with quality according to its competitors,

- Identify, which components of organisational model of quality management are more important than others are,

- Analyse the level of organisational efficiency of quality management from the viewpoints of busin ess and quality criteria of funning business.

\section{Requirements of the Construction Industry}

Compared with many other industries, the construction industry faces high complexity, high uncertainty and discontinuity, as well as many restrictions (cf. Barrie/Pauls on 1992, Thompson 1989). For re-engineering processes in this industry, it is necessary to take these special requirements into account and develop solutions that help contractors to cope better with these challenges, thus improving the companies' competitive standing. The high degree of complexity results to a large extent from the high number of different -mostly small - companies taking part in any single project. People and resources are at the same time part of two (or even more) organis ations: the ir respective company and the project organisation. Therefore, a high effort is required for coordination and communication, especially since the amount of exchanged information is rather high, and there may be large distances between a work site and the company offices. Company re-engineering should therefore deliver effective coordination processes that support easy communication. Good solutions require the implementation of entire processes throughout different companies. This is not easy, especially since each cooperation is only temporary. Uncertainties and risks are caused by weather and site conditions, as well as by the fact that many projects are subject to changes after the work has already started. Due to the singularity of each project, there is always some degree of unpredictability involved. This means that re-engineering processes although to some extent standardised for efficiency reasons, must provide enough flexibility and robustness to cope with unexpected situations and changes. For example, procurement activities can be standardised and automated to a large extent. This leads to reduced effort for processing procurement documents and communication with the supplier, as well to a lower number of mistakes, i.e. to higher quality. However, for special supplies or very urgent needs, it must be possible to do whatever is necessary to get a required material or service, without being forced to follow the standard procedures. Such exceptions should not lead to great disturbances in the system. Since there is usually a clear distinction between designing and planning on one side, and project execution on the other side, it is very difficult for a single construction company to improve the overall project, since many important decisions have already been made when the contractor enters the project. Many advantages can be achieved, when it is possible to integrate the planning and execution phase more tightly and improve the overall processes involving designers, engineers and contractors as a whole.

\section{Success factors for Company re-engineering}

The organisation of most companies is still structured according to the principle of function orientation. Based on that principle, organisational units are responsible for a small number of activities which they perform for the overall spectrum of products and services in the company. Thus we may find departments for production, procurement, sales, accounting, etc. Traditionally, each of these departments has its own specialised information system with its own database.

In such a function-oriented organisation, a business process, e.g. the process from a customer order to the shipping of a finished product, crosses many departmental borders. This leads to inefficient, time-consuming, and expensive process execution, and it increases the number of errors. The paradigm of Company re-engineering therefore leads to a fundamental re-design of the organisation and its information systems. Organisations are structured according to business processes rather than functions, i.e. one organisational unit is responsible only for a small number of products or services, but for all or most processes related to them (cf. Scheer 1994). Information systems need to be re-designed, as well. Isolated, function-oriented systems are to be replaced by integrated systems supporting the entire business processes. Centralised, mainframe-based systems cannot meet the demands of modern, processoriented, decentralised organisation. Such organisations require flexible solutions, such as client-server systems. In the construction industry, the picture is more complex. On the one hand, we find functionally oriented company structures, e.g. the administration and central services of a company. On the other hand, there is the project organisation for each construction project, with a temporary character, involving many different companies, each of which also has its own structure. It is therefore not as easy as in the stationary industry to re-structure a company's organis ation according to the principle "process instead of function", but a 
thorough analysis of the processes is required to develop adequate structures and systems for each company. Although the Re-engineering Principle approach has been connected with promises of drastic improvements (such as cost reductions as high as $70 \%$ ), there have been many projects which did not fulfil the expectations, because important aspects have not been considered. The main success factors for re-engineering of Construction Companies from the quality viewpoint project are:

- Management commitment,

- Detailed analysis of customer requirements,

- Development of concrete strategies and quantifiable objectives,

- Sufficient resources for the project,

- Early involvement and participation of all people in the company,

- Development of process-oriented thinking in the company's culture,

- $\quad$ Systematic procedures (procedural model),

The last point is of great importance. Before any Construction Company starts to implement the company reengineering this company must create own model for re-engineering, because each construction company is unique and each site has own characteristics in one word models must be created to fit for every single company.

For creation of any model for the re-engineering of Construction Company from the quality viewpoint should include the following:

- Definition of strategy and objectives

- Identification of core processes

- Analysis of weak points

- Definition of business process owners

- Detailed development of processes

- Implementation of processes

- Evaluation and improvement of processes

\section{Approach to Quality management as a basis for Company Re-engineering}

The inclusion of construction companies in the international market, the care for reputation, that the enterprise/company profit with the quality management system and permanent development, places the politics of quality to the base of the professional politics of that enterprise/company.

The basic aim of the quality management system is to increase the process efficiency or rather lower the loss of efficiency. This is why we determine where in the system the quality process was used efficiently and where quality losses were made on the basis of mass and quality balances. Possible measures, which the quality management system can encompass, include the fields of organizational measures, the use of modern equipment and techniques as well as the introduction of new technologies.

An organization should implement an effective quality management system in order to help protect human health and the environment from the potential impacts of its activities, product or services; and to assist in maintaining and improving the quality of the environment and quality of life. Having a QMS can help an organization provide confidence to its interested parties that:

- A management commitment exists to meet the provisions of its policy, objectives and targets;

- Emphasis is placed on prevention rather than corrective action;

- Evidence of reasonable care and regulatory compliance can be provided ; and

- The systems design incorporates the process of continual improvement.

Regarding this starting point we propose a systemic quality management framework for Company re-engineering as showed in figure 1; A Systemic Quality Management Framework for company renovation. 


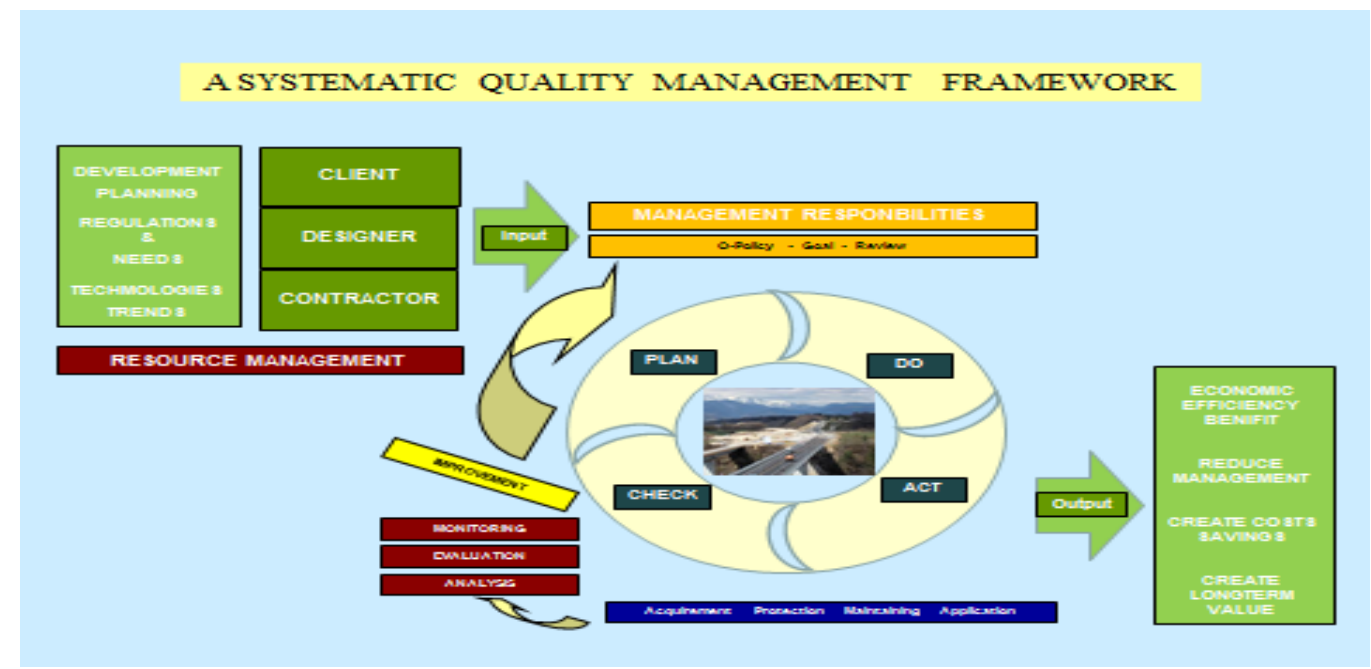

Figure 1: Systematic Quality Management Framework for company renovation

An organization whose management system incorporates a QMS has a framework to balance and integrate economic and quality interests. An organization that has implemented a QMS can achieve significant competitive advantages. Economic benefits can be gained from implementing a quality management system. These should be identified in order to demonstrate to interested parties, especially shareholders, the value to the organization of good quality management. It also provides the organization with the opportunity to link quality objectives and targets with specific financial outcomes and thus to ensure that resources are made available where they provide the most benefit in both financial and quality terms. Figure 2: Quality Management for Companies working in road sector our second proposal.

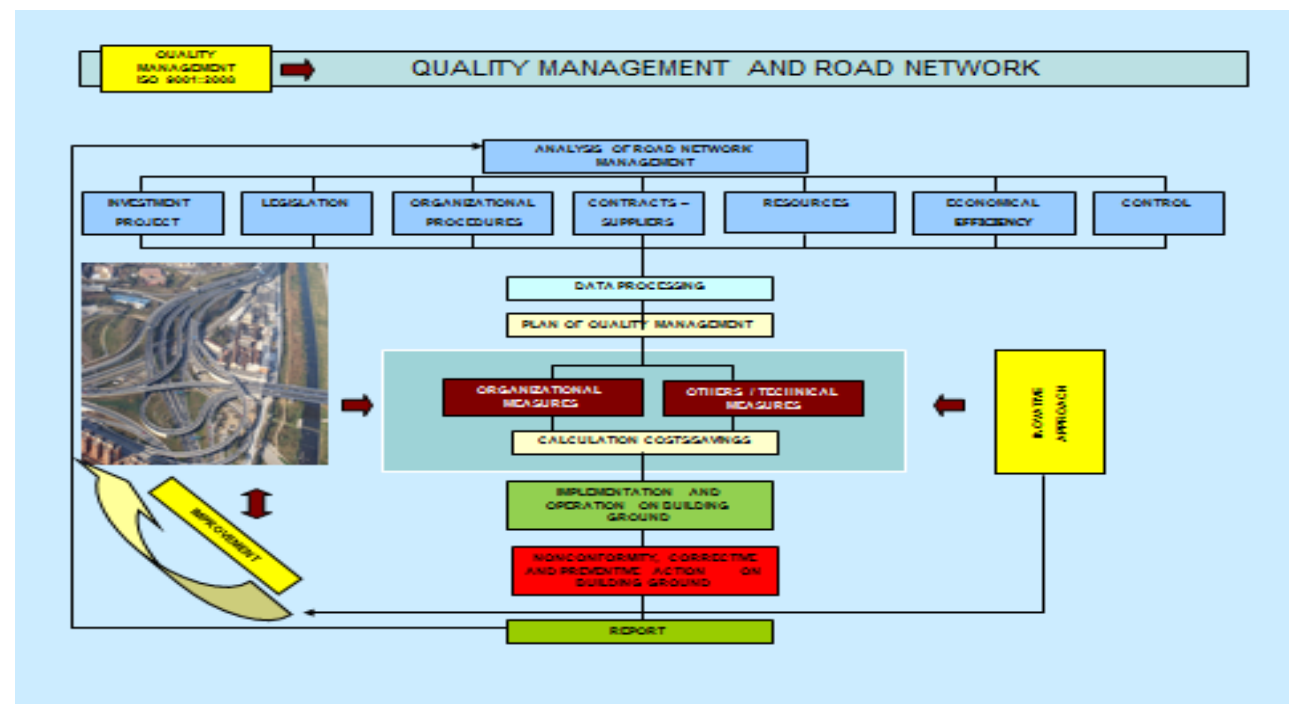

Figure 2: Quality Management for Companies working in road sector.

For any possible company re-engineering in any Construction Company the Quality Assurance and Qu ality Control department must have the main position in any Company because Construction Companies can survive in this competitive market only producing products which meet clients' expectations fulfilling main criteria of final product time, cost, and quality. Figure 3: Quality Assurance and Quality Control department model. 
QUALITY ASSURANCE AND CONTROL SYSTEM

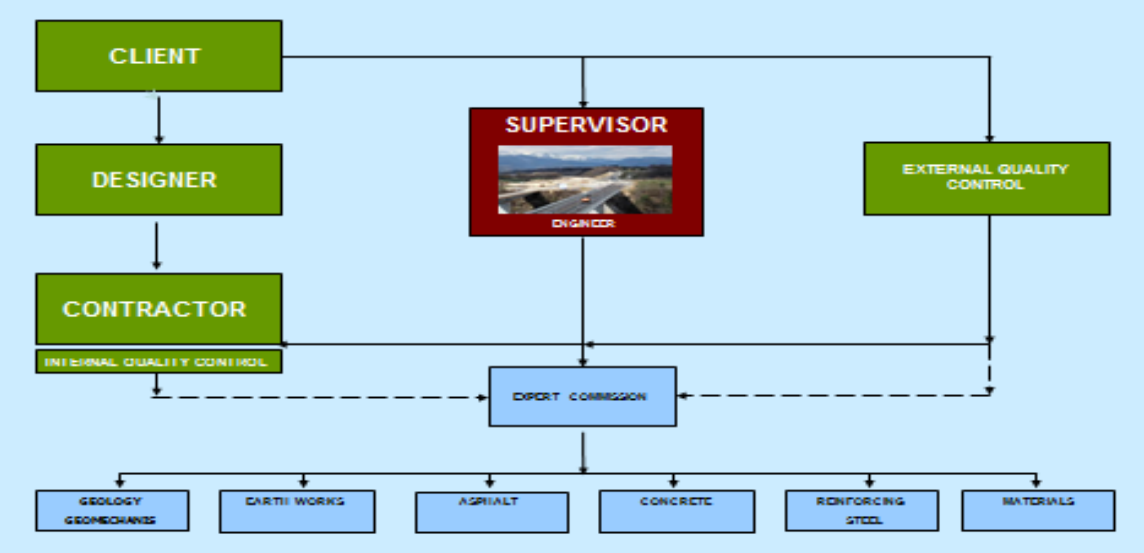

Figure 3: Quality Assurance and Quality Control model

\section{Economic efficiency and benefits of quality managements systems at Construction Companies.}

In economics, the term economic efficiency refers to the use of resources so as to maximize the production of goods and services. An economic system is said to be more efficient than another (in relative terms) if it can provide more goods and services for society without using more resources. In absolute terms, a situation can be called economically efficient if:

- No one can be made better off without making someone else worse off (commonly referred to as Pareto efficiency).

- No additional output can be obtained without increasing the amount of inputs.

- Production proceeds at the lowest possible per-unit cost.

These definitions of efficiency are not exactly equivalent, but they are all encompassed by the idea that a system is efficient if nothing more can be achieved given the resources available [6]. Improving the effectiveness and efficiency of the quality management system can influence positively the financial results of the organization. Management system standards (MSSs) have spread in an unprecedented manner in the last few years. Thus, there are now many companies that rely on more than one such standard to establish the criteria for organizational management systems (MSs) [7]. Figure 4 presents benefits of multiple Management Standards including Quality Management System. 


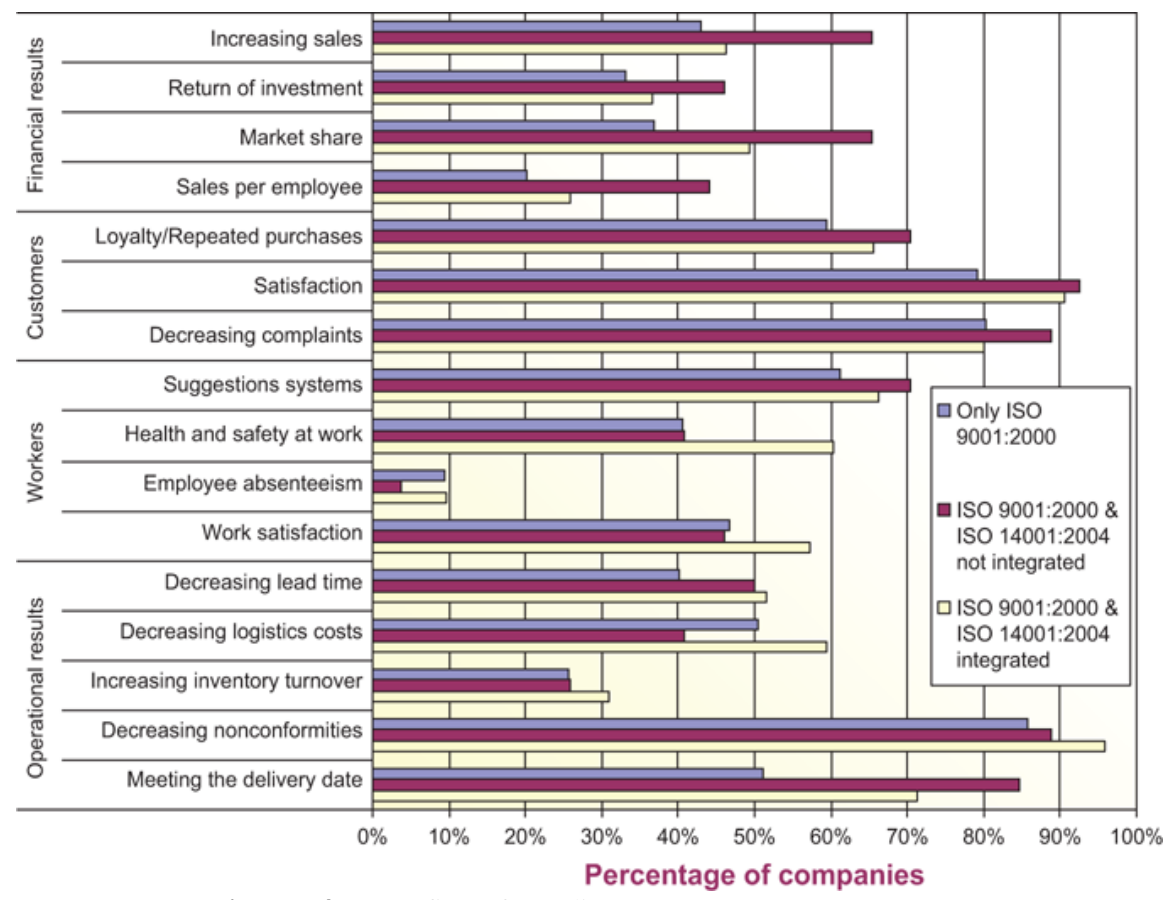

Figure 4: Benefits of Quality Management System [7]

The results show that organizations with multiple MSSs (Management System Standards) actually perceive more benefits from the implementation of ISO 9001 than those that implemented that standard only. Furthermore, organizations with integrated management systems (IMSs) also report higher levels of ISO 9001 benefits compared to those organizations with the ISO 9001 certificate only, but generally not when compared to their counterparts with separate standardized MSs (Management System) [7].

\section{Conclusion}

Management should not focus on short-term benefits, but on long-term consequences of quality aimed at long-term efficiency and effectiveness of the company's business and quality activities during the process of company Reengineering or renovation. Currently, organizations implementing either ISO 9001:2008, or TQM do not need to comment on overall quality performance. Neither standard comments on the degree of control exercised, the approach taken, or the effectiveness of that control during the Company renovation. Both standards advocate that participating organizations should have viewed each particular function of their business process and have applied a self-formulated quantitative/qualitative analysis to the function in question. It is this requirement for "selfformulation" that fails to provide positive incentives to the organization to add a level of independently verifiable transparency to the analysis process [2]. The potential economic benefits associated with an effective Company renovation on the quality basis approach include but not limited to:

- Assuring customers of commitment to demonstrable quality management;

- Maintaining good public/community relations;

- Satisfying investor criteria in regard to quality completed product ;

- Obtaining insurance at reasonable cost;

- Enhancing image and market share;

- Meeting vendor certification criteria;

- Improving cost control;

- Reducing incidents that result in liability;

- Demonstrating reasonable care on each department inside the construction company;

- Conserving input materials and energy;

- Facilitating the attainment of permits and authorizations;

- Fostering development and sharing environmental solutions;

- Improving industry-government relations 
The decisions we make today will determine the operating conditions of economy and people's life, at least for a few decades. The expected development of Construction Companies is a challenge, responsibility at the same time an exceptional opportunity of each manager working in this field [8].

\section{References}

[1] Gashi. E, Kralj. D „, Ecconomic effieciency in roadnetwork as a result of quality management system” Pp 1-7, Ist Albanian Conference on roads-Tirana, September-2012,

[2] Gashi. E, Kralj. D „, Quality of Road Network in Kosovo as a Consequence of Administration Innovating ” Pp 1-7, 5 WSEAS Congress-Malta, September-2012,

[3] Nelson, M. Lee, A. Cooper, R. Kagioglou, M. Fleming, A. „Process Re-engineering in the Construction

Industry - buzzword or reality?"' November 2010, pp 1-10,

[4] Ardhaldjian, R. \& Fahner, M. (1994). „Using Stimulation in the Business Process Reengineering Effort.

Industrial Engineering '.'26 (27). Pp 60-61,

[5] Allweyer ,T. Babin-Ebell.T, Leinenbach, S. Scheer, A-W. „Model-Based Re-engineering in the European Construction Industry”' May 2009 Pp 1-11,

[6] http://www.emeraldinsight.com/Insight/11.06.2010

[7] Mulej M., System Thinking UM-EPF, Maribor, (1992)

[8] Henigman, S. et al. Kakovost gradnje in vzdrževanja cestne infrastrukture. 2008. 9. slovenski kongres o cestah in prometu, Portorož, 22.-24. oktober 2008. pp. 1 - 15

[9] http://en.wikipedia.org/wiki/Economic efficiency/17.05.2012

[10] Casadesus, M. et al. Synergies in standardized management systems: some empirical evidence. 2011. The TQM Journal, Vol. 23 Iss. pp $73-86$ 